\title{
Process optimization for efficient convergence in large optics fabrication
}

Chang Jin Oh, Andrew E. Lowman, Hubert M. Martin, Greg A. Smith

Chang Jin Oh, Andrew E. Lowman, Hubert M. Martin, Greg A. Smith, "Process optimization for efficient convergence in large optics fabrication," Proc. SPIE 10706, Advances in Optical and Mechanical Technologies for Telescopes and Instrumentation III, 107060D (10 July 2018); doi: $10.1117 / 12.2314350$

Event: SPIE Astronomical Telescopes + Instrumentation, 2018, Austin, Texas, United States 


\title{
Process optimization for efficient convergence in large optics fabrication
}

\author{
Chang Jin Oh *a, Andrew E. Lowman ${ }^{\mathrm{a}}$, Hubert M. Martin ${ }^{\mathrm{b}}$, Greg A. Smith ${ }^{\mathrm{a}}$ \\ ${ }^{a}$ College of Optical Sciences, University of Arizona, Tucson, AZ, USA 85721; \\ ${ }^{\mathrm{b}}$ Steward Observatory, University of Arizona, Tucson, AZ, USA 85721
}

\begin{abstract}
Large optic fabrication is a delicate and time consuming process. Obtaining a large prime optic is often in the critical path of a project and poses a serious risk to both the schedule and budget. The Optical Engineering and Fabrication Facility (OEFF) at the College of Optical Sciences, the University of Arizona, has developed a new way of optimizing its large optic fabrication process for maximum efficiency in convergence. The new process optimization takes the amount of stock material removal, tool characteristics, metrology uncertainty, optic prescription, optic material properties, and resource availability as input parameters and provides an optimized process along with an achievable convergence.

This paper presents technical details of the new process optimization and demonstrates performance on $6.5 \mathrm{~m}$ mirror fabrication at the University of Arizona. Two case studies for an $8.4 \mathrm{~m}$ GMT off-axis primary mirror segment and a $3.1 \mathrm{~m}$ TMT convex secondary mirror fabrication are also presented.
\end{abstract}

Keywords: Large optics, fabrication, testing, aspheric, computer controlled polishing

\section{INTRODUCTION}

Large optics are in high demand for their light collecting power and resolution, which are directly related with system performance. Large optic fabrication is a delicate and time consuming process because it pursues an extremely high accuracy over a large dimensional scale while adopting an inherently slow material removal process such as polishing. Therefore, obtaining a large prime optic is often in the critical path of a project and is considered a risky item for both schedule and budget. The Optical Engineering and Fabrication Facility (OEFF) at the College of Optical Sciences, the University of Arizona has developed a new way of optimizing its large optics fabrication process for maximum efficiency in convergence, with its output providing a consistent and deterministic projection of the large optics fabrication process. The new process optimization takes the amount of stock material removal, tool characteristics, metrology uncertainty, optic prescription, optic material properties, and resource availability as the input parameters and provides an optimized process along with an achievable convergence. The OEFF group applied this new optimized process to a $6.5 \mathrm{~m}$ primary mirror fabrication project carried out at the University of Arizona and successfully demonstrated its performance. As a result, the $6.5 \mathrm{~m}$ primary mirror fabrication project finished in 11 months using only two different sizes of tools. Overall it was three times more efficient than past $6.5 \mathrm{~m}$ mirror fabrication projects [1], [2] performed at the University of Arizona, when considering actual processing time.

This paper presents technical details of the new process optimization and two case studies on an $8.4 \mathrm{~m}$ GMT off-axis primary mirror segment and a $3.1 \mathrm{~m}$ TMT convex secondary mirror.

\section{KEY ELEMENTS OF EFFICIENT LARGE OPTICS PROCESSING}

There are many key elements critical for successful large optic fabrication including blank shape and material, tooling and deterministic material processing, stable metrology support, precision metrology, and efficient resource allocation. We discuss the detailed processes, capabilities, and available technology at the University of Arizona, which will be different from other organizations.

*cjoh@optics.arizona.edu; phone 1520 626-5454; www.optics.arizona.edu

Advances in Optical and Mechanical Technologies for Telescopes and Instrumentation III, edited by Ramón Navarro, Roland Geyl, Proc. of SPIE Vol. 10706, 107060D · C 2018 SPIE CCC code: $0277-786 \mathrm{X} / 18 / \$ 18 \cdot$ doi: $10.1117 / 12.2314350$ 


\subsection{Blank shape and material}

Optical polishing is typically done by removing small amounts of materials through a polishing process. Material removal rates are highly dependent on the material properties of blank. Knowing the material removal rate precisely will make the polishing process deterministic and will converge the optical fabrication process more efficiently and reliably.

Large mirror blanks are constructed with light-weighted structures to reduce overall weight. Generally, light-weighted structures leave so-called quilting, imperfect features on the optical surface having mid spatial frequency corresponding to the spatial scale of the light-weighted structure. To achieve a fine optical surface, getting rid of quilting is very important.

Thermal properties of the blank material are also important because the thermal response is important for metrology. Low expansion glass or ceramics like ULE and Zerodur are very thermally stable. The University of Arizona produces large light-weighted spin cast mirror made from Ohara E6 borosilicate glass which is reasonably thermally stable. Figure 1 shows a $6.5 \mathrm{~m}$ light-weighted mirror cast by Richard F. Caris Mirror Laboratory at the University of Arizona. There are other materials such as $\mathrm{SiC}$, composites, etc.

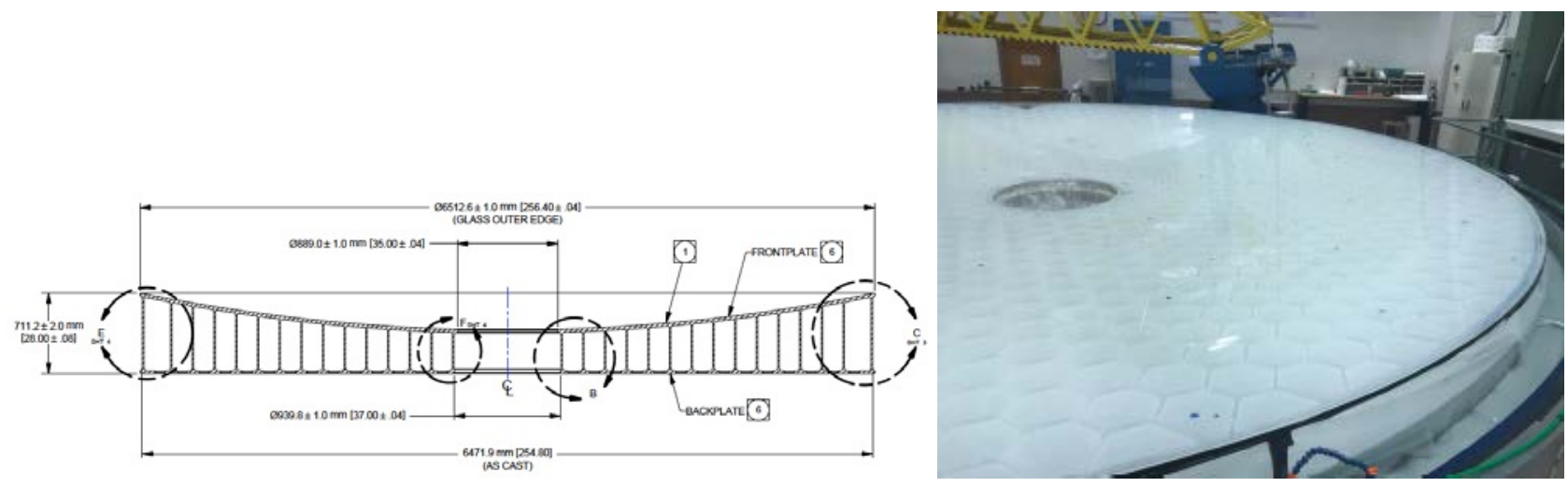

Figure $1.6 .5 \mathrm{~m}$ light-weighted mirror cast at the University of Arizona. In the photograph, taken right after the mirror was polished out, the honeycomb structure is clearly visible.

\subsection{Tooling and material processing}

Material removal is proportional to the size of the tool, polishing pressure, and speed. However, there is a limitation to the size of the tool mostly due to the allowable misfit between the polishing tool and local aspheric optical surface. There are a few ways of mitigate misfit in polishing.

A stressed lap is an active polishing tool that deforms its tool surface using actuators according to the position of the tool on the mirror surface. Since the stressed lap uses many actuators and sensors to deform its shape correctly, it can be made very stiff, which is very effective for smoothing but very complicated. Some large mirror fabrication projects including the Multiple Mirror Telescope (MMT), Magellan I \& II, Large Binocular Telescope (LBT) and Giant Magellan Telescope (GMT) segment 1 were polished by a $1.2 \mathrm{~m}$ stressed lap.

A flexible tool is a tool having its bending stiffness optimized such that the tool deforms its shape to the local mirror shape passively. Since flexible tools do not use any actuators or sensors, they are simple to build and operate, and yet allows reasonable smoothing. However, there is practical limitation in size to achieve good smoothing and accommodate misfit. Some large mirror fabrication projects including the Discovery Channel Telescope (DCT), Hobby Eberly Telescope Wide Field Corrector (HET/WFC), Daniel K. Inouye Solar Telescope (DKIST), and Tokyo Atacama Telescope (TAO) were polished by $600 \mathrm{~mm}$ to $150 \mathrm{~mm}$ passive flexible tools. Figure 2 shows examples of stressed lap and flexible tools.

Most fabrication at the University of Arizona is done on computer controlled polishing (CCP) machines. The $4.2 \mathrm{~m}$ machine shown in Figure 2 is a gantry style, while the $6.5 \mathrm{~m}$ is a swingarm CCP. These types of machines are critical for efficient deterministic processing. 

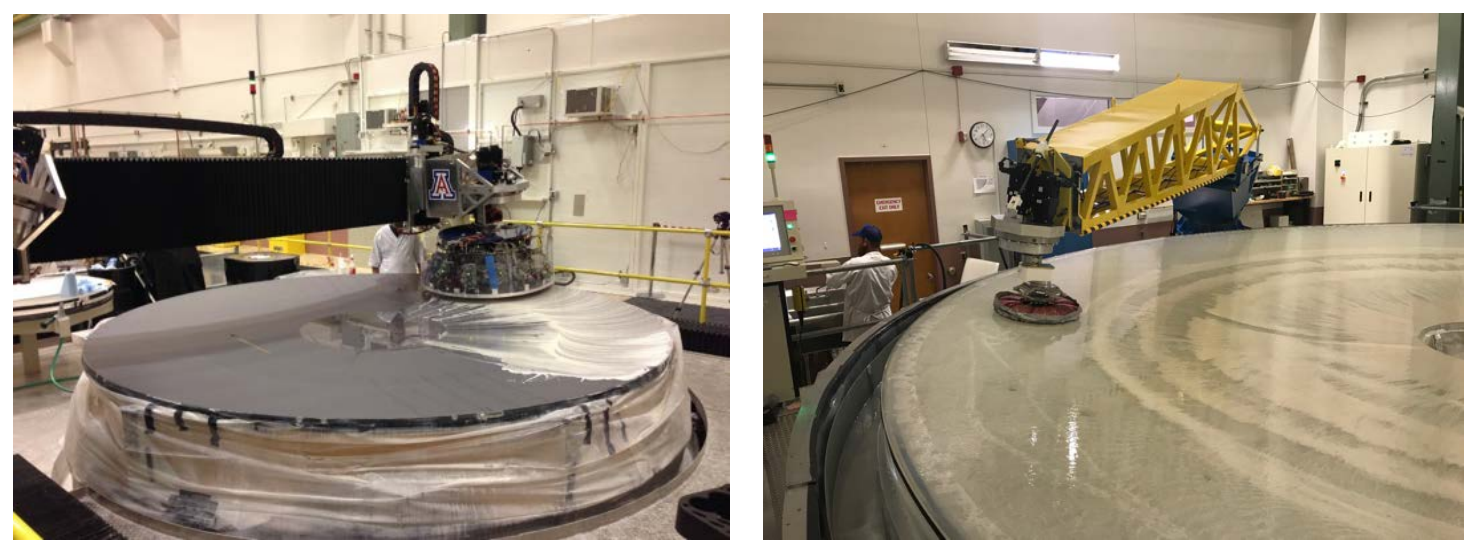

Figure 2. (Left) Stressed lap operating on 4.2m DKIST primary. (Right) Passive lap operating on a $6.5 \mathrm{~m}$ mirror.

\subsection{Metrology support and precision metrology}

Precision stable metrology is a key for a successful fabrication process. Stability of the metrology support is very important to not affect the shape of the optic through many cycles of measurement over a long fabrication process. The metrology support is frequently used as a fabrication support. Since it is a mechanically constructed system holding a large optic, changes in the support force due to mechanical or thermal instability will introduce unwanted optical surface distortion. To mitigate risk in the metrology support, thorough engineering and analysis along with many sensors of various types are applied to the design as well as actual hardware.

Figure 3 shows the hydraulic support used for the $4.2 \mathrm{~m}$ DKIST mirror fabrication. The DKIST mirror is a $75 \mathrm{~mm}$ thick meniscus mirror; high stability in the support was very important. Throughout the project, the support demonstrated approximately $0.1 \mathrm{~N}$ RMS stability.

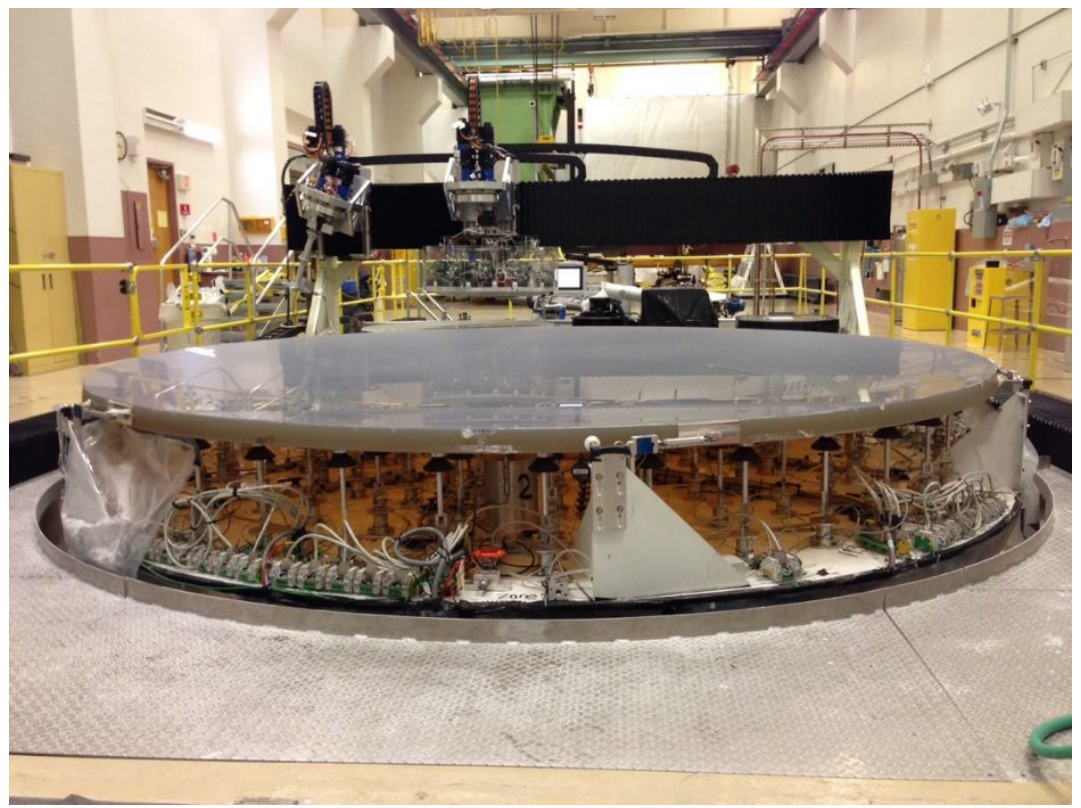

Figure 3. DKIST hydraulic support. 
Effective precision metrology for various fabrication stages is critical for efficient large optics fabrication. Optical fabrication begins with generating, typically using a diamond tool, to get approximately the net shape of the required optical surface before going through coarse/fine grinding and optical polishing. Generally, until the surface is polished, the surface is matte and does not reflect much light, making precision optical tools such as interferometry difficult to apply or reducing their accuracy. The shape of the optical surface can also limit the metrology approach. Convex surfaces make light diverge so that complicated interferometry or special coordinate measurements like the University of Arizona-developed Swingarm Optical CMM are necessary. Highly aspheric or freeform surfaces require high dynamic range with high accuracy. To overcome these types of metrology challenges, the University of Arizona has developed various kinds of metrology schemes. Table 1 shows some examples of metrology tools used to measure various shapes and conditions of an optical surface.

Table 1. Metrology tools available for different types of surfaces and phases of fabrication.

\begin{tabular}{|c|c|c|c|l|}
\hline Metrology & Surface Condition & $\begin{array}{c}\text { Surface } \\
\text { Shape }\end{array}$ & $\begin{array}{c}\text { Uncertainty } \\
\text { (um RMS) }\end{array}$ & \multicolumn{1}{|c|}{ Comment } \\
\hline Laser Tracker & Ground/Polished & $\begin{array}{c}\text { Convex/ } \\
\text { Concave }\end{array}$ & $2-5$ & Coarse spatial resolution \\
\hline IR SCOTS & Fine Ground/Initial Polished & Concave & 0.5 & Fine spatial resolution \\
\hline $\begin{array}{c}\text { Visible } \\
\text { SCOTS }\end{array}$ & Polished & Concave & 0.25 & $\begin{array}{l}\text { High dynamic range; relatively high } \\
\text { uncertainty in low order figure }\end{array}$ \\
\hline $\begin{array}{c}\text { Swingarm } \\
\text { Optical CMM }\end{array}$ & Ground/Polished & $\begin{array}{c}\text { Convex/ } \\
\text { Concave }\end{array}$ & 0.01 & $\begin{array}{l}\text { Excellent metrology tool for convex } \\
\text { measurement }\end{array}$ \\
\hline Interferometry & Polished & $\begin{array}{l}\text { Convex/ } \\
\text { Concave }\end{array}$ & 0.005 & $\begin{array}{l}\text { Requires null corrector; sub-aperture } \\
\text { stitching used for flat or convex }\end{array}$ \\
\hline
\end{tabular}

\subsection{Resource allocation}

Besides the technical elements addressed above, resource allocation is another critical element. Large optics fabrication takes a long time. To maximize efficiency, available resources must be applied properly and work schedule must be planned carefully, then implemented and executed precisely. These routine activities include metrology, data reduction, polishing run design, polishing tool preparation, polishing run execution, and cleaning the optic. Additionally, machine maintenance, metrology calibration, and any foreseeable downtime such as holidays, vacations, etc. must be considered from a management perspective.

\section{PROCESS OPTIMIZATION}

Recently the University of Arizona finished a $6.5 \mathrm{~m}$ primary mirror fabrication project for an astronomical telescope. Measured surface figure is plotted as a function of time in Figure 4. 


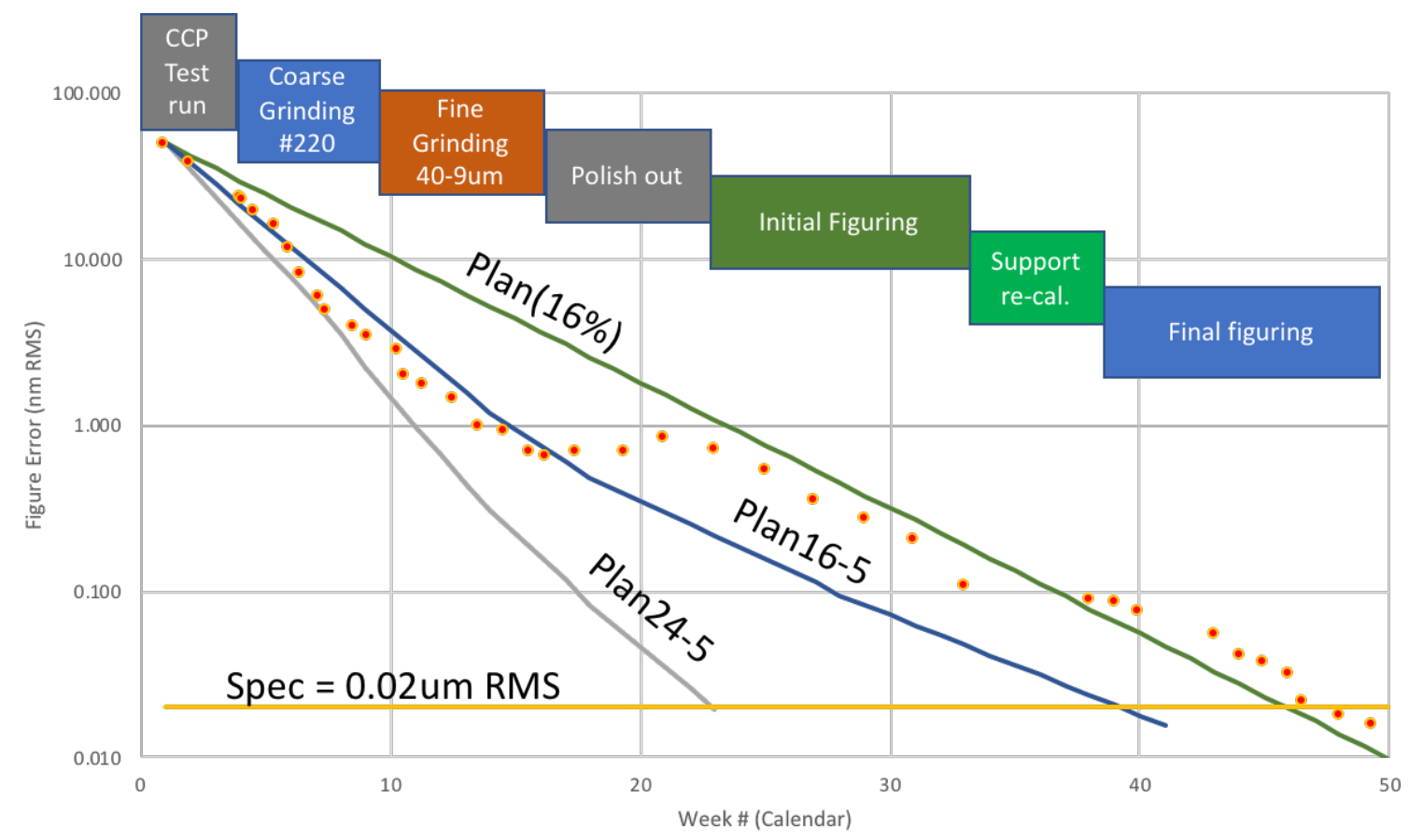

Figure 4. Planned and achieved (orange dots) surface figure as a function of schedule. "Plan (16\%)" was the original plan.

When the projected was initiated, the fabrication schedule was estimated based on a past project. The average rate of surface figure error improvement, which was $16 \%$ per each work week, was used as a baseline. The estimated projected completion was approximately 46 work weeks. Figure 4 also shows plans for 16 hours per day, 5 days per week (Plan16-5) and 24 hours per day, 5 days per week (Plan24-5). The actual plan followed was closest to Plan16-5.

As the project was begun, the actual progress was marked along with plan. The project was successfully completed with the duration of the project very well matched to the initial plan. However, by reviewing this performance, the team found that planning using a single monotonous average rate might not be optimal because the surface figure improvement during coarse and fine grinding phase converged much faster than figuring by polishing. This makes sense since the material removal rate in grinding is much higher than in polishing. We also observed that the transition phase from grinding to polishing took longer than expected due to the slow polish out process as well as the metrology change over between two distinct surface conditions.

To improve the performance of the polish out process and to create a more seamless metrology transition between grinding and polishing, we have developed a more efficient polishing out process and improved IR deflectometry. Figure 5 shows results from our new polish out process. The new process marked as P203/P103 removes material much faster and leaves a much smoother surface compared to a conventional polishing process. Figure 6 shows IR deflectometry results, which agree reasonably well with the final interferometry map. This will be discussed in detail at an upcoming SPIE conference [3]. IR deflectometry may be used to take the surface from fine grinding to final figuring (comfortably within the capture range of interferometry) without requiring any intermediate metrology methods. 

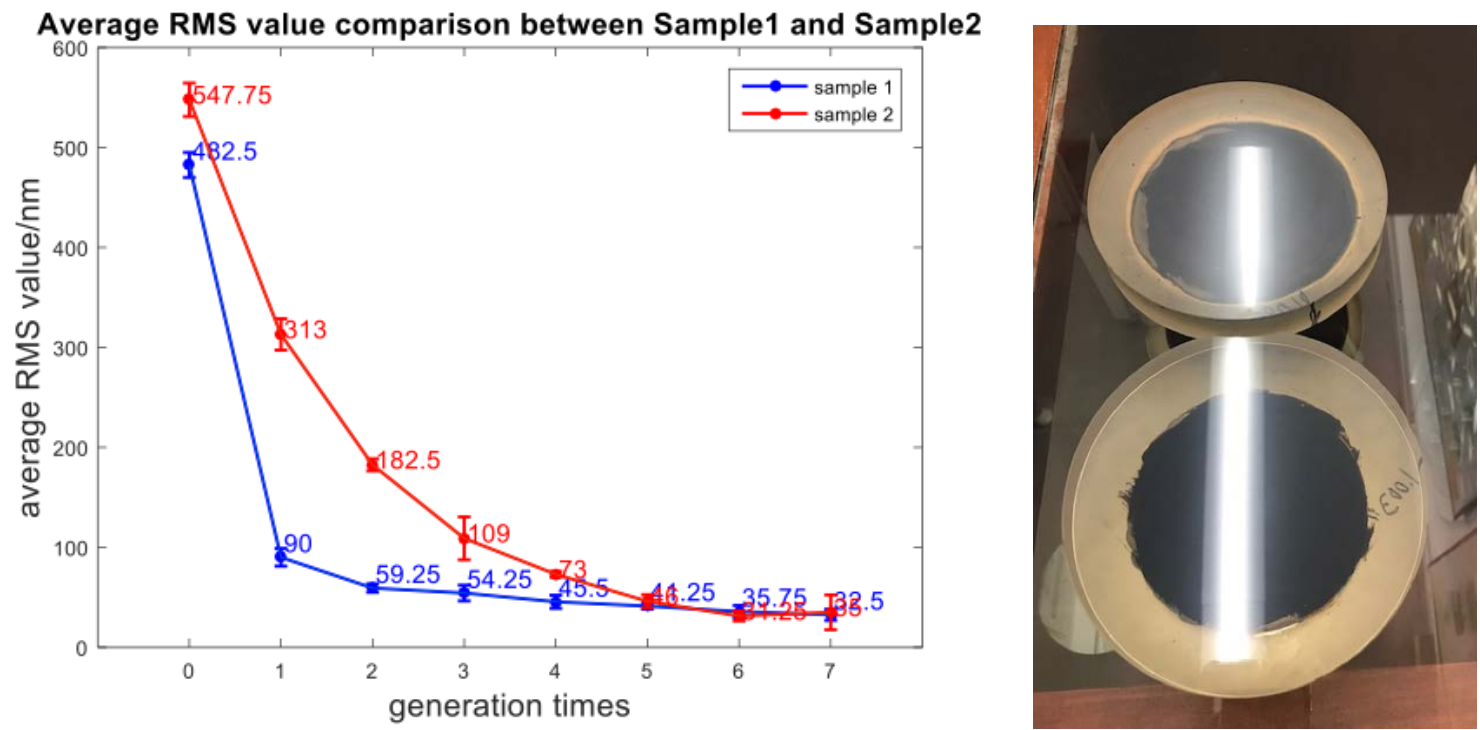

Figure 5. Improved polish-out process. (Left) Plot showing convergence: sample 1 is our new rapid polish out P203/P103 process, while sample 2 is a conventional process. (Right) Top surface had conventional processing; bottom surface used P103 and has improved reflectivity (smoother surface).
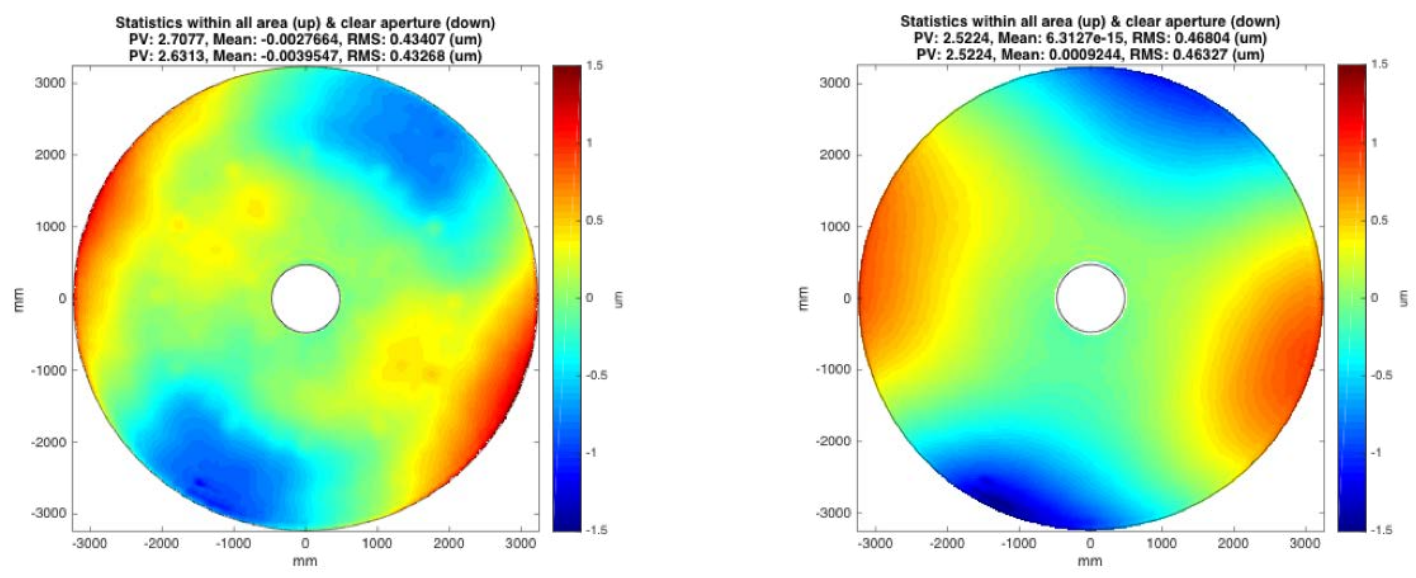

Figure 6. (Left) IR deflectometry surface map. (Right) Interferometry surface map.

Considering the new development in polish out process and metrology for transition from grinding to polishing, the overall process has been re-optimized. The optimized process is shown in Table 2. Compared to Plan16-5 in Figure 4, the grinding phase matches extremely well to the optimized prediction, and the polish out and figuring process also match well. 
Table 2. Re-optimized fabrication process.

\begin{tabular}{|c|c|c|c|c|c|c|c|c|c|c|c|}
\hline Fabrication & & & & & & & Metrology & & & Output & \\
\hline Process & Grit & $\begin{array}{c}\text { Removal } \\
\text { Rate }\end{array}$ & Tool \#1 & Tool\#2 & $\begin{array}{c}\text { Bulk } \\
\text { Material }\end{array}$ & $\begin{array}{l}\text { Schedule } \\
\text { Efficiency }\end{array}$ & Primary & $\begin{array}{l}\text { Uncertainty } \\
\text { (um) }\end{array}$ & Redundancy & $\begin{array}{l}\text { Removal } \\
\text { (um) }\end{array}$ & $\begin{array}{l}\text { Run time } \\
\text { (hr) }\end{array}$ \\
\hline Coarse Grinding & 220 & -1200 & 500 & 300 & 300 & 0.75 & Laser Tracker & 5 & N/A & 465 & 357.5 \\
\hline Fine Grinding & 40 & -800 & 500 & 300 & 150 & 0.75 & IR SCOTS & 1 & $\begin{array}{l}\text { Laser } \\
\text { Tracker }\end{array}$ & 153 & 176.5 \\
\hline Fine Grinding & 25 & -500 & 500 & 300 & 75 & 0.75 & IR SCOTS & 0.5 & $\begin{array}{l}\text { Laser } \\
\text { Tracker }\end{array}$ & 76.5 & 141.2 \\
\hline Initial Polishing & P203 & -250 & 500 & 300 & 35 & 0.85 & 2 SCOTS & 0.25 & $\begin{array}{l}\text { Laser } \\
\text { Tracker }\end{array}$ & 35.75 & 152 \\
\hline Initial Polishing & P103 & -100 & 500 & 300 & 15 & 0.85 & IR SCOTS & 0.25 & $\begin{array}{l}\text { Visible } \\
\text { SCOTS }\end{array}$ & 15.75 & 254.8 \\
\hline Final Figuring & $\mathrm{C} 1$ & -20 & 300 & 150 & 5 & 0.65 & Interferometry & 0.005 & $\begin{array}{c}\text { Visible } \\
\text { SCOTS } \\
\text { Total }\end{array}$ & $\begin{array}{r}5.015 \\
746\end{array}$ & $\begin{array}{r}405.75 \\
1487.75\end{array}$ \\
\hline
\end{tabular}

\section{CASE STUDIES}

Two case studies were performed - an $8.4 \mathrm{~m}$ GMT off-axis segment fabrication, and a $3 \mathrm{~m}$ class convex mirror fabrication - to generate an idea of what would be achievable for project planning purposes.

\subsection{4m GMT off-axis primary mirror segment fabrication}

The Richard F. Caris Mirror lab at the University of Arizona is fabricating $8.4 \mathrm{~m}$ primary mirror segments for the Giant Magellan Telescope (GMT) project. The GMT primary mirror consists of 7 segments, one $8.4 \mathrm{~m}$ on-axis mirror for the center segment and the remaining 6 mirrors $8.4 \mathrm{~m}$ off-axis segments that surround the center segment. One off-axis segment is completed; currently, the second off-axis segment is being polished. There are 5 more segments to be fabricated, and an optimized process has been studied and compared to the $6.5 \mathrm{~m}$ mirror fabrication result. Figure 7 shows the result for the case study.

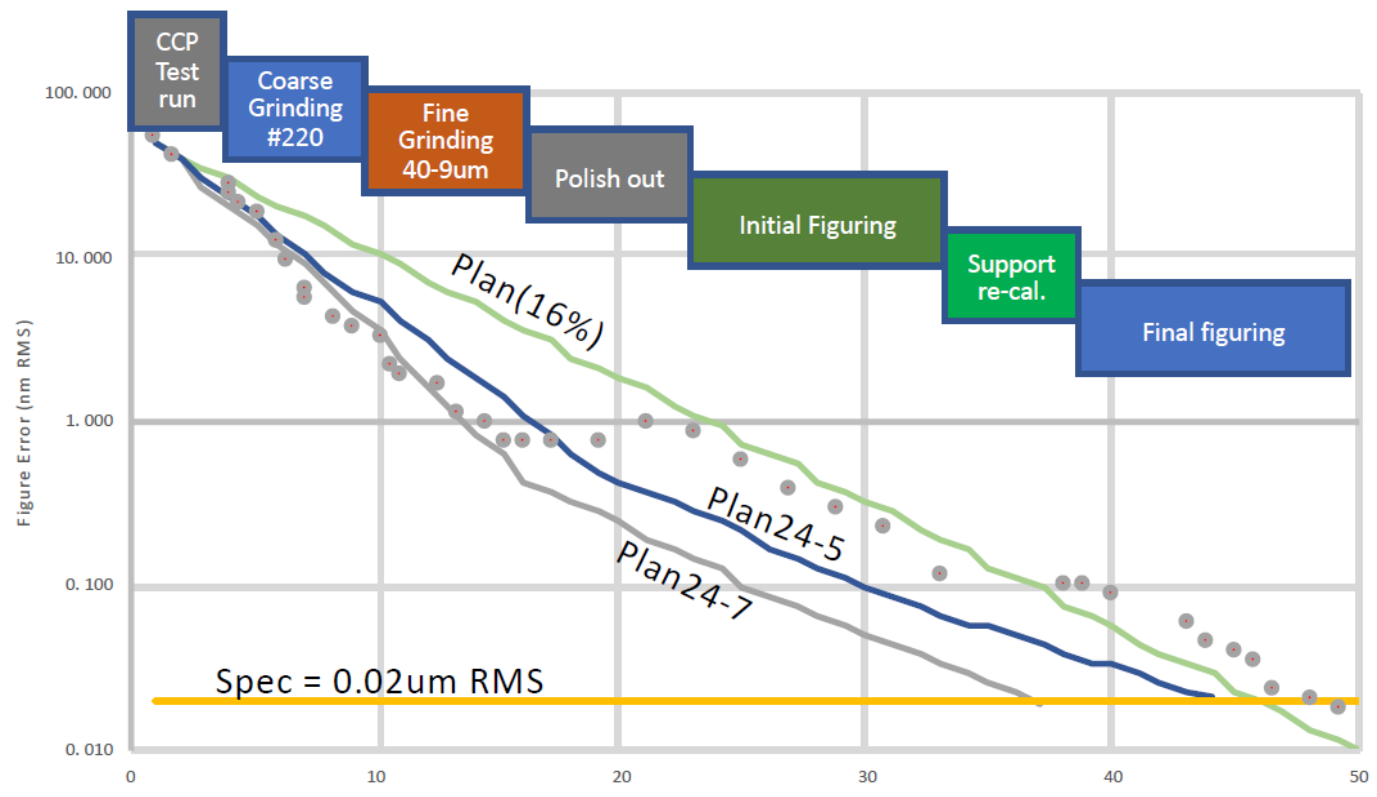

Figure 7. Plan for the GMT off-axis segment case study. For comparison, the dots are actual results from the latest $6.5 \mathrm{~m}$ mirror fabrication. 
The result indicates $8.4 \mathrm{~m}$ GMT off-axis segment might be fabricated in approximately 45 work weeks. In this study any potential down time such as maintenance, holiday, vacation, etc. has not been considered and if there is any foreseeable downtime then it could be added to the optimized result. By looking at the surface area, $8.4 \mathrm{~m}$ GMT off-axis mirror segment is 1.72 time larger than a $6.5 \mathrm{~m}$ mirror; however the actual runtime for GMT segment is 1.8 time longer than a $6.5 \mathrm{~m}$ mirror. One difference is that GMT fabrication uses a P24-5 schedule, but the $6.5 \mathrm{~m}$ mirror used a P16-5 schedule. Another difference is tooling. Since the GMT off-axis segments have much higher aspheric departure compared to a $6.5 \mathrm{~m}$ mirror, the tool size is limited to $400 \mathrm{~mm}$ although the hardware allows a faster speed. Actual data from the current processing has been used for the optimization.

\subsection{3m class convex aspheric secondary mirror fabrication}

Three extremely large telescope projects currently under construction adopt $3 \mathrm{~m}$-class highly aspheric convex secondary mirrors. Fabrication of large convex mirrors is challenging because the highly aspheric convex shape is difficult to measure and because tooling size is limited by misfit of the tool. The University of Arizona has developed efficient metrology tools include Swingarm Optical CMM and sub-aperture stitching interferometry for large convex mirror testing, with measurement uncertainty as low as sub-10nm RMS. Swingarm Optical CMM and sub-aperture stitching interferometry have demonstrated their accuracy and efficiency through multiple challenging large convex mirror fabrication projects such as $1.4 \mathrm{~m}$ off-axis convex mirrors, $0.9 \mathrm{~m}$ convex secondary mirror and a meter-class opaque convex mirror.

This case study used the mirror prescription of $3.1 \mathrm{~m}$ Thirty Meter Telescope (TMT) convex secondary mirror. Table 3 shows data used for the process optimization.

Table 3. Optimized fabrication process for a $3.1 \mathrm{~m}$ convex secondary mirror.

\begin{tabular}{|c|c|c|c|c|c|c|c|c|c|c|c|}
\hline Fabrication & & & & & & & Metrology & & & Output & \\
\hline Process & Grit & $\begin{array}{l}\text { Removal } \\
\text { Rate }\end{array}$ & Tool \#1 & Tool\#2 & $\begin{array}{c}\text { Bulk } \\
\text { Material }\end{array}$ & $\begin{array}{l}\text { Schedule } \\
\text { IEfficiency }\end{array}$ & Primary & $\begin{array}{l}\text { Uncertainty } \\
\text { (um) }\end{array}$ & Redundancy & $\begin{array}{c}\text { Removal } \\
\text { (um) }\end{array}$ & $\begin{array}{l}\text { Run time } \\
\text { (hr) }\end{array}$ \\
\hline Coarse & & & & & & & & & & & \\
\hline Grinding & 220 & -1200 & 300 & 200 & 300 & 0.75 & Laser Tracker & 5 & N/A & 465 & 327 \\
\hline Fine & & & & & & & & & Laser & & \\
\hline Grinding & 40 & -800 & 300 & 200 & 150 & 0.75 & $\mathrm{SOCg}$ & 1 & Tracker & 153 & 215.9 \\
\hline Fine & & & & & & & & & Laser & & \\
\hline Grinding & 25 & -500 & 300 & 200 & 75 & 0.75 & SOCg & 0.5 & Tracker & 76.5 & 172.7 \\
\hline $\begin{array}{c}\text { Initial } \\
\text { Polishing }\end{array}$ & P203 & -250 & 300 & 200 & 35 & 0.85 & $\mathrm{SOCg}$ & 0.25 & $\begin{array}{c}\text { Laser } \\
\text { Tracker }\end{array}$ & 35.75 & 161.4 \\
\hline Initial & 1200 & -250 & 300 & 200 & נכב & & & & Laser & & \\
\hline Polishing & P103 & -100 & 200 & 100 & 15 & 0.85 & $\mathrm{SOCi}$ & 0.05 & Tracker & 15.15 & 344.1 \\
\hline Figuring & C1 & -20 & 200 & 100 & 5 & 0.65 & Interferometry & 0.005 & $\mathrm{SOCi}$ & 5.015 & 570.1 \\
\hline & & & & & & & & & Total & 745.4 & 1791.2 \\
\hline
\end{tabular}

For tooling, a flexible tool has been chosen to minimize potential quilting, with the tool size defined based on misfit to the optical surface. For metrology, laser tracker and Swingarm Optical CMM have been selected for grinding, and Swingarm Optical CMM and sub-aperture stitching interferometry have been selected for polishing. As a work schedule the P16-5 plan has been selected because night time can be used for Swingarm Optical CMM operation along with comfortable resource allocation without downtime in the scheduled work hours. Figure 8 shows the process optimization result for $3 \mathrm{~m}$ class convex secondary mirror fabrication.

The result predicts it will take approximately 50 work weeks for completion although the optical surface area is much lower than for a $6.5 \mathrm{~m}$ mirror. This is mostly because the tool size is small due to high asphericity and efficiency is lower for the more complicated sub-aperture interferometry in the final figuring phase. Yet a deterministic process for a $3 \mathrm{~m}$ class convex secondary mirror in 50 work weeks is outstanding performance with low risk from the perspective of telescope project management. 


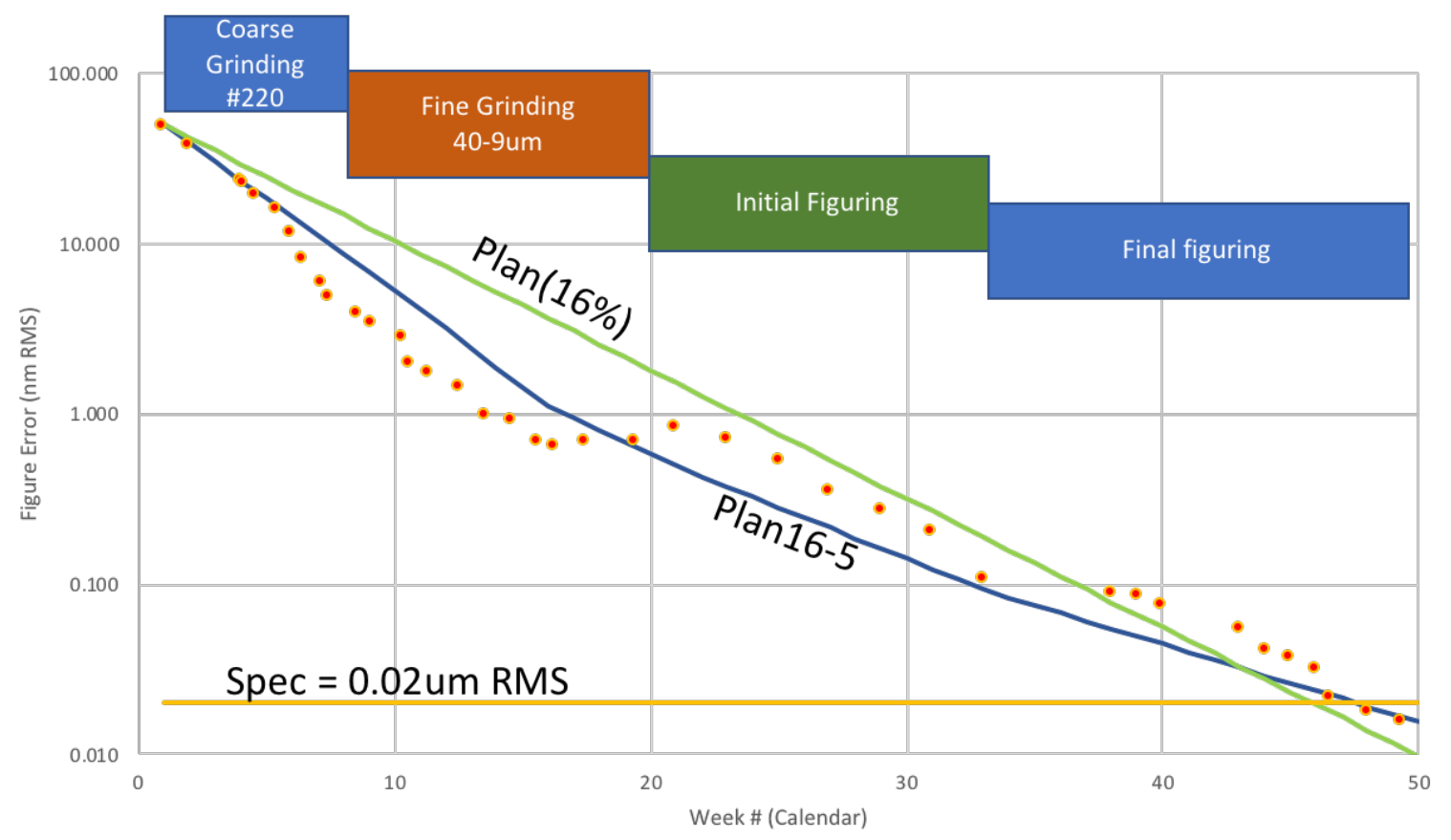

Figure 8 . Plan for the $3.1 \mathrm{~m}$ convex mirror case study. For comparison, the orange dots are actual results from the latest $6.5 \mathrm{~m}$ mirror fabrication.

\section{SUMMARY}

The Optical Engineering and Fabrication (OEFF) group at the College of Optical Sciences, University of Arizona has developed a new methodology to optimize its large optics fabrication process by considering material properties of the blank, optical surface shape, tooling, metrology uncertainty, and resource availability. Effectiveness of the new process optimization methodology has been demonstrated through $6.5 \mathrm{~m}$ mirror fabrication performance.

Two case studies on $8.4 \mathrm{~m}$ GMT off-axis primary mirror segment fabrication and $3.1 \mathrm{~m}$ TMT convex secondary mirror fabrication have been performed using real parameters. The results demonstrated predictable processes are feasible and could be used as an excellent project management tool.

\section{ACKNOWLEDGEMENT}

The authors would like to thank to Mr. Bill Anderson and Ms. Xiangyu Guo for rapid polishing experiments to develop the $\mathrm{P} 203$ and $\mathrm{P} 103$ processes.

\section{REFERENCES}

[1] H. M. Martin, R. G. Allen, J. R. P. Angel, J. H. Burge, W. B. Davison, S. T. DeRigne, L. R. Dettman, D. A. Ketelson, W. C. Kittrell, S. M. Miller, P. A. Strittmatter, S. C. West, "Fabrication and measured quality of the MMT primary mirror," Proc. SPIE 3352 (1998).

[2] H. M. Martin, R. G. Allen, J. H. Burge, L. R. Dettman, D. A. Ketelson, W. C. Kittrell, S. M. Miller, "Polishing of a $6.5 \mathrm{~m} \mathrm{f} / 1.25$ mirror for the first Magellan telescope," Proc. SPIE 3739 (1999).

[3] H. Yoo, G. A. Smith, C. J. Oh, A. E. Lowman, M. Dubin, "Improvements in the Scanning Long-wave Optical Test System (SLOTS)," Proc SPIE 10742-48 (2018). 